\title{
Occurrence and multiple-level ecological risk assessment of pharmaceuticals and personal care products (PPCPs) in two shallow lakes of China
}

$\mathrm{Na} \mathrm{Liu}$

Chinese Research Academy of Environmental Science

Xiaowei Jin ( $\nabla$ jinxiaowei07@mails.ucas.ac.cn )

China National Environmental Monitoring Center https://orcid.org/0000-0002-4932-3623

Zheng Yan

Chinese Society for Environmental Science

Ying Luo

Chinese Research Academy of Environmental Sciences

Chenglian Feng

Chinese Research Academy of Environmental Sciences

Zhiyou Fu

Chinese Research Academy of Environmental Sciences

Zhi Tang

Chinese Research Academy of Environmental Sciences

\section{Fengchang Wu}

Chinese Research Academy of Environmental Sciences

John P. Giesy

University of Saskatchewan

\section{Research}

Keywords: PPCPs, concentration, multiple-level, risk assessment, China, Tai Lake, Baiyangdian Lake, probabilistic, Asia

Posted Date: April 27th, 2020

DOI: https://doi.org/10.21203/rs.2.23424/v2

License: (c) (1) This work is licensed under a Creative Commons Attribution 4.0 International License.

Read Full License 
Version of Record: A version of this preprint was published at Environmental Sciences Europe on May 6th, 2020. See the published version at https://doi.org/10.1186/s12302-020-00346-1. 


\section{Abstract}

Background: Management of pharmaceuticals and personal care products (PPCPs) in the environment has become a social issue. In the present study, concentrations of 140 PPCPs at 20 sites in Baiyangdian Lake and Tai Lake from 2016 to 2017 were analyzed by Ultra Performance Liquid Chromatography Mass Spectrometer (UPLC-MS). Risk quotients (RQ) were calculated for each detected chemical at all sites and prioritization indices $(\mathrm{PI})$, based on maximum $\mathrm{RQ}$, were calculated. To assess the risk of chemicals that identified high priority (PI>1), a more accurate method of joint probability curves (JPCs) was applied.

Results: A total of 42 PPCPs were identified and quantified detected in the two lakes, with maximum concentrations ranged from 0.04 to $889 \mathrm{ng} / \mathrm{L}$. Among these, seven PPCPs were identified as high or moderate risk pollutants for at least one site, 3 in Tai Lake and 5 in Baiyangdian Lake. Carbamazepine posed significant ecological risk at all 20 sites, such that more attention should be paid to that drug. Based on results of the JPCs, sulfamethoxazole, caffeine, diethyltoluamide, and carbamazepine were categorized as high or intermediate risks.

Conclusion: Occurrences and distributions of PPCPs were different in the two lakes. Multiple-level risk assessment from simple to more complex was appropriate in chemical risk management.

\section{Background}

Pharmaceuticals are defined as prescription, over the counter and veterinary therapeutic drugs that are used to prevent or treat diseases in humans and animals, while personal care products (PCPs) are used mainly to improve grooming during daily life [1]. Total usage of antibiotics in China for 2013 was estimated to be approximately 162,000 tons, which means that China consumed 9 times more antibiotics than the USA (17,900 tons) and 150 times more than the UK (1,060 tons) [2]. The proportion of the global total of PCPs consumed in China is approximately $6.5 \%$, which is exceeded only by the United States of America (19.1\%) and Japan (9.4\%) [3]. A growing body of literature demonstrates that pharmaceuticals and personal care products (PPCPs) are present in surface waters of China, particularly in those receiving effluents from wastewater treatment plants (WWTPs). Although PPCPs are detected in surface waters at relatively small concentrations, they and their metabolites are biologically active and can, during longterm exposure, affect non-target aquatic organisms including endocrine disruption, genotoxicity, carcinogenicity, fetal development [4,5]. Data on occurrences of PPCPs in aquatic environments in China, revealed that concentration of these PPCPs in waters occurred at concentrations of $\mu \mathrm{g} / \mathrm{L}-\mathrm{ng} / \mathrm{L}[6,7]$. Diclofenac and ibuprofen were identified as priority PPCPs based on previous screening level risk assessments. Presence and concentrations of pharmaceuticals in European surface waters were surveyed [8] and based on the results of an optimization of screening-level risk assessment, 29 compounds were indicated to present significant risks to aquatic environments.

Based on the region and scale of assessment, due to differences in density of human population, development level of the regional economy, and hydrology in different environmental compartments, 
several sets of priority compounds were expected. In most cases, hot spots for pollution by PPCPs were waters affected by megacities with greater densities of population [6]. For example, East China consumed 38,800 tons of antibiotics in 2013, while Northwest China consumed only 2,360 tons [2]. Relationships between catchment-specific sociodemographic parameters and biomarkers in wastewater generated for respective catchments were explored [9]. Results showed that biomarkers of caffeine had positive correlations with indices of relative socioeconomic advantage and disadvantage (IRSAD), concentrations of pregabalin were negatively correlated with IRSAD, while concentrations of carbamazepine, cotinine, ibuprofen, and sulfamethoxazole exhibited insignificant correlations with IRSAD. Therefore, so that effective management measures could be implemented, it was deemed necessary to identify PPCPs most likely to pose risks in various regions.

Lake Tai (Ch: Taihu) is the largest shallow freshwater lake in China [10], with mean depth of $1.94 \mathrm{~m}$, surface area of $2338 \mathrm{~km}^{2}$ and volume of 4.4 billion $\mathrm{m}^{3}$ [11], is located in the Yangtze Delta in Eastern China, which is one of the most heavily urbanized and industrialized areas of China [12]. In addition to being a popular recreational and tourist attraction, it serves as an important source of water for drinking, irrigation of agriculture and use by industries [13]. Baiyangdian Lake is the largest lake and most hydrologically strategic freshwater lake on the North China Plain and is an important ecological function zone of the Xiong'an New Area [14]. Baiyangdian Lake is a nearly closed, inter-locking lake which collects rainwater, floodwater and runoff from over $20 \%$ of the plain $[15,16]$. In addition to providing direct water supply for domestic, agricultural and industrial use, the lake is a source of livelihood, via fishing, tourism, transportation and reed/lotus farming, for more than 200,000 inhabitants around its shore $[17,18]$. Because of the invaluable socio-ecological functions and services of the lake, it is vital to develop a sustainable management strategy to preserve its environment, ecology and hydrology.

In the last few years, risks posed by PPCPs to ecological parameters have been assessed in Lakes Tai $[10,12,19,20]$ and Baiyangdian $[21,22]$. However, because assessments were based solely on screeninglevel risk quotients $(R Q)$, occurrences and environmental risks of PPCPs in the two lakes were not well described and their sources were not understood, Thus, more detailed and accurate understandings of occurrences and risks posed by PPCPs in these two large lake systems were needed. The objectives of this study were to: 1) Determine presence and concentrations of PPCPs in Tai and Baiyangdian Lakes, which represented lakes in two regions with different hydrology, climate conditions and social-economic structures; 2) Ranking PPCPs that have potential risk for aquatic organisms; 3) Conduct accurate ecological risk assessment based on multiple species for priority chemicals.

\section{Materials And Methods}

\section{Target Chemicals and Sample collection}

Based on reported uses of PPCPs in livestock farms, WWTPs, and environment media in China, 140 frequently detected PPCPs (Table S1) were selected as target chemicals. Two sampling campaigns were conducted in June 2016 for Tai Lake and June 2017 for Baiyangdian Lake. Ten water samples from 10 
locations were collected from each study area (Fig. 1). Two liters of surface water were collected from each location into brown glass bottles that had been pre-cleaned with methanol and deionized water, then rinsed with water from the sampling site before collection. All samples were kept at $4{ }^{\circ} \mathrm{C}$, and target PPCPs were extracted from water samples within 4 days of collection [22].

\section{Preparation and instrumental analysis}

Before extraction, samples were filtered through $0.45 \mu \mathrm{m}$ GHP membrane filters, to which $0.2 \mathrm{~g} \mathrm{Na}{ }_{2} \mathrm{EDTA}$ was added, and spiked with $20 \mathrm{ng}$ each of surrogate standards. Filtered water was extracted by solidphase extraction (SPE) with tandem cartridges: Oasis WAX $(150 \mathrm{mg} ; 6 \mathrm{~mL})$ weak anion exchange mixedmode cartridge coupled with Oasis HLB $(500 \mathrm{mg} ; 6 \mathrm{~mL})$ hydrophilic-lipophilic balance cartridges. Cartridges were activated and conditioned with $6 \mathrm{~mL}$ methanol and $6 \mathrm{~mL}$ ultrapure water. Samples of water were passed through the tandem cartridges at a flow rate of $1 \mathrm{~mL} / \mathrm{min}$. After extraction, the columns were separated, rinsed with $6 \mathrm{~mL}$ water, and dried for $30 \mathrm{~min}$. Elution was performed sequentially by use of 6-8 mL $1 \%(\mathrm{v} / \mathrm{v})$ ammonia in methanol (WAX cartridge) or $2 \%(\mathrm{v} / \mathrm{v})$ formic acid in methanol (HLB cartridge), 6-8 mL methanol-MTBE (1/9, v/v) and 6-8 $\mathrm{mL}$ methanol- dichloromethane (2/8, $\mathrm{v} / \mathrm{v}$ ) for both WAX and HLB cartridges. Elution fractions from WAX and HLB cartridges were mixed and dried under a gentle nitrogen stream, then redissolved in $1 \mathrm{~mL}$ of ultrapure water [23-25].

Extracts were analyzed by UPLC-MS (LC-Agilent Technologies 1290 Infinity, MS-ABI Triple Quadrupole 6495; CA). Chromatographic separation of analytes was performed by use of an Agilent ZORBAX Eclipse Plus $\mathrm{C} 18(2.1 \times 100 \mathrm{~mm}, 1.8 \mu \mathrm{m})$. For the positive electrospray ionization mode $(\mathrm{ESI})$, the mobile phase $\mathrm{A}$ contained $0.02 \%$ acetic acid in water, while mobile phase $B$ was acetonitrile. During negative ESI, the mobile phase $A$ contained water, while mobile phase $B$ was acetonitrile. A binary gradient with a flow rate of $0.3 \mathrm{~mL} / \mathrm{min}$ was used. Injection volume was $10 \mu \mathrm{L}$. To avoid analytical interference and/or cross contamination, equipment and containers were rinsed with methanol and water before use. Field blanks and procedural blanks were analyzed with extraction to control travel contamination and laboratory contamination [21]. Linearity of calibration curves was confirmed $\left(r^{2}>0.99\right)$ with the concentration of standards ranged from 0.005 to $100 \mu \mathrm{g} / \mathrm{L}$, and mean relative recoveries of three replicates spiked at 50 $\mathrm{ng} / \mathrm{L}$ varied from 75.2 to $121.0 \%$. Limit of detections (LOD) or limits of quantification (LOQ) were defined as the concentration at which the signal-to-noise ratios $(S / N)$ were greater than 3 or 10 , respectively.

\section{Characterization of risks}

\section{Environmental toxicity information.}

Toxic potencies of PPCPs to non-target organisms were mainly obtained from the ECOTOX Knowledgebase (https://cfpub.epa.gov/ecotox/search.cfm) developed by the US EPA, following principles of accuracy, relevance and reliability [26-29]. Because the habitat and geographical distribution of species do not have a significant influence on the assessment of hazard [30,31], data for non-native species were used in this study. In this study, data on toxic potencies were selected by use of hierarchical methods [32] and data on chronic toxic potencies expressed as no observed effect concentrations 
(NOECs) or $10 \%$ effect concentration $\left(\mathrm{EC}_{10}\right)$ for the most sensitive endpoints. If a NOEC or $\mathrm{EC}_{10}$ was not available, a lowest observed effect concentration (LOEC) or median effect concentration $\left(E_{50}\right)$ was used with assessment factors (AFs) of 2 or $10[6,32]$.

\section{Assessment of risks}

Ecological risks of PPCPs in surface waters were assessed by use of a methodology developed within the NORMAN Association [33] and previous studies [8, 33-36]. Chronic, sublethal, risk quotients (RQ) were calculated by dividing measured concentration of individual chemicals in waters by the predicted no effect concentration (PNEC; Equation 1). Preliminary assessment ranks for risks posed by PPCPs was developed by classifying PPCPs posing di minimis $(R Q<0.1)$, lesser $(0.1 \leq R Q<1)$, moderate $(1 \leq R Q<10)$ and greater $(R Q \geq 10)$ risks $[6,37]$. Furthermore, to identify PPCPs of greatest concern in the two lakes a prioritization index (Pl; Equation 2) was calculated, as the result of $\mathrm{RQ}_{\max }$ calculated for the maximum concentration, multiplied by the frequency of PNEC exceedance (Equation 3). This index allows to smooth out the impact of compounds with high RQ but rarely detected [34]. (see Equations 1-3 in the Supplementary Files)

Where $C_{m}$ is the measured concentration for a single chemical measured at a sample; PNEC is the predicted no effect concentration derived from the most sensitive toxicity data with assessment factor of 10,20 , or 100 depending on test endpoints of NOEC or $\mathrm{EC}_{10}, \mathrm{LOEC}_{1} \mathrm{EC}_{50}[6,32] ; F$ is the frequency of PNEC exceedance; $n$ is the number of sites with concentrations above PNEC and; $N$ is the total number of sampling sites for a chemical; $P /$ is prioritization index; $R Q_{\max }$ is risk quotient calculated based on maximum concentration.

PNECs introduce an element of subjectivity and are driven by a few reports of effects reported to occur at small concentrations, which might not be repeatable. Thus, it is desirable to corroborate risks predicted by use of joint probability curves (JPCs). In this method, measured concentrations and chronic toxicity data on various species to PPCPs were compiled and transformed to probits by fitting appropriate distributions. Linear regression of the two data sets can then be used to calculate probabilities of concentrations causing adverse effects to a specified proportion (\%) of species [38]. Each point on the curve represents both the probability that the chosen proportion of species will be affected (magnitude of effect) and the frequency with which that magnitude of effect would be exceeded in surface waters (exceedance probability). JPCs were developed by use of the Probabilistic Risk Assessment Tool (PRAT) [39]. In this assessment, the area under the risk curve (AUC) was estimated for each combination of focal species and exposure scenario, and then used to categorize risks as either de minimis, lesser, intermediate or greater by risk products (Equation 4) for $0.25 \%, 2 \%$, and 10\% [40]. (see Equation 4 in the Supplementary Files)

\section{Statistical analysis}


During the analysis, concentrations were set to 0 if less than LOD, and one half of the LOQ if less than LOQ. Frequency of detection and mean concentrations of PPCPs were calculated using Microsoft Excel 2010 (Microsoft China, Beijing). Figures for exposure distributions were developed by use of Origin Pro 9.1 (Northampton, MA, USA). Prior to correlation analyses, tests of normality were carried out by use of SPSS Statistics V20.0 (IBM, Armonk, NY, USA). Normality for each concentration was confirmed by use of the Shapiro-Wilk test and homogeneity of variance was confirmed by use of Levine's test.

\section{Results And Discussion}

\section{Occurrence and spatial variations}

Of the 140 target PPCPs, 42 were detected in the two lakes at one or more sampling sites. Among these compounds, five PPCPs, carbamazepine, diethyltoluamide, lidocaine, cotinine, chlorpheniramine, and triadimefon were found in both lakes. Approximately $11.5 \%$ (16 out of 140 ) of the analyzed PPCPs in Tai Lake were detected at the concentrations above the limit of detection levels, and circa 22.3\% (31 out of 140 ) in Baiyangdian Lake. Concentrations of PPCPs in surface waters from Tai and Baiyangdian Lakes are summarized in Fig. 2. There were differences in the number, types and concentrations of PPCPs detected in waters of the two lakes. This result might be caused by several factors, including differences in use and release, removal efficiency of the WWTPs, degradation rate, temperature and dilution of receiving waters $[8,41]$. Compared with Baiyangdian Lake, Tai Lake possess richer water resources and higher temperature that could result in PPCPs being diluted and more quickly being degraded. Consumption of caffeine is associated with aspects of financial capability [9], so it was more frequently detected in Tai Lake, which located in the eastern developed area of China. The bactericide, triadimefon and insect repellent, diethyltoluamide were consumed more in agricultural regions, near Baiyangdian Lake. Maximum concentrations of antibiotics sulfamethoxazole, griseofulvin, and lincomycin reported in Baiyangdian Lake were $34.5,12.2$, and $113.4 \mathrm{ng} / \mathrm{L}$, while the antibiotic trimethoprim was $0.6 \mathrm{ng} / \mathrm{L}$ observed in Tai Lake. These results were consistent with amounts of antibiotics used in the two regions [2].

Total concentrations of the 16 PPCPs detected at ten sites in Tai Lake, ranged from 26.02 to $42.72 \mathrm{ng} / \mathrm{L}$, with a median concentration of $31.11 \mathrm{ng} / \mathrm{L}$. Maximum concentrations of individual chemicals ranged from $0.04 \mathrm{ng} / \mathrm{L}$ for famotidine to $25.77 \mathrm{ng} / \mathrm{L}$ for caffeine, and detection of frequencies of $10 \%-100 \%$. Nine chemicals, caffeine, valsartan, diethyltoluamide, cotinine, carbamazepine, chlorpheniramine, trimethoprim, and triadimefon, were positively detected in all 10 samples. Concentrations of carbamazepine, ranging from 0.63 to $1.86 \mathrm{ng} / \mathrm{L}$, were similar to concentrations previously reported for Tai Lake, which ranged from 0.24 to $8.74 \mathrm{ng} / \mathrm{L}$ [19]. However, the maximum concentration of ibuprofen was found to be $1.48 \mathrm{ng} / \mathrm{L}$, which was less than those mean concentrations reported previously for Tai Lake (65.3 ng/L) [19], Liao River (246 ng/L) [23] and the Peal River (1417 ng/L) [42]. Diclofenac, propranolol and erythromycin were not detectable in all water samples during this study, have been previously reported to occur at relatively great concentrations [19]. 
In Tai Lake, coefficients of variation (CV; $\mathrm{CV}=$ mean concentration/standard deviation) for concentrations of individual PPCPs ranged from $12 \%$ to $258 \%$. This result indicated spatial variations and large differences among chemicals. Spatial variation might result from a combination of distances of sampling sites from sources of emissions and variations in volumes of discharges [43]. For example, the predominant pollutant, caffeine, was present at relatively great concentrations (up to $25.77 \mathrm{ng} / \mathrm{L}$ ) at Meiliang Bay (T5, T8, T9, T10) near a densely populated and scenic spot [44] and a relatively stable, thermal stratification that had been established for some days [45]. Eight PPCPs occurred at the greatest concentrations at T7, because the Yincungang River receives domestic wastewater from a densely populated and urbanized area [45]. These results were in general agreement with previous observations in sediments [20], where caffeine was the dominant pollutant near the Yincungang River estuary, and PPCPs in the west of Tai Lake exhibited greater concentrations than those other locations sites.

Analyzed occurrence of 31 PPCPs detected in Baiyangdian Lake, total concentrations at ten sites ranged from 622 to $2781 \mathrm{ng} / \mathrm{L}$, with a median of $1421 \mathrm{ng} / \mathrm{L}$. Although most individual compounds occurred at lesser concentrations, total concentrations of PPCPs exceeded $1 \mu \mathrm{g} / \mathrm{L}$ at eight locations. Mean concentrations of individual chemicals ranged from 0.79 to $329.18 \mathrm{ng} / \mathrm{L}$. Concentrations of diethyltoluamide (329.18 ng/L), methylparaben (201.47 ng/L), florfenicol (196.74 ng/L), metformin $(183.14 \mathrm{ng} / \mathrm{L})$ were greatest among PPCPs. Frequencies of detection for the 31 PPCPs were 10\%-100\%, among which 24 chemicals were detected at all the ten locations. Concentrations ranged from 0.94 to $113.40 \mathrm{ng} / \mathrm{L}$. These results are consistent with those of previous studies where 22 antibiotics were observed in waters of Baiyangdian Lake and tributaries [21]. In that previous study, antibiotics occurred widely in waters samples, with sulfamethoxazole occurring at the greatest concentrations, with a maximum concentration of $940 \mathrm{ng} / \mathrm{L}$, which was much greater than that of $34.54 \mathrm{ng} / \mathrm{L}$, observed in this study.

All 31 PPCPs were found at B10, and the total concentrations of combined PPCPs was $2780 \mathrm{ng} / \mathrm{L}$. The most likely reason for this is that location B10 is located near the lakeshore, at a frequently visited, scenic spot, and near the estuary of Fuhe River that receives huge amount of wastewater from Baoding City. Results of previous studies indicated that sewage discharged from Baoding City with over one million residents is likely to be the main source of PPCPs to Baiyangdian Lake [47, 48]. In addition, relatively great concentrations of PPCPs were found at B9 $(1856.9 \mathrm{ng} / \mathrm{L})$ and B1 $(1751.7 \mathrm{ng} / \mathrm{L})$. As expected, least concentrations of PPCPs $(622-1,190 \mathrm{ng} / \mathrm{L})$ in water samples were observed in the middle of the lake (B2, B3, B4, B5), where there was little direct influence by human being activities. These studies demonstrated that human activities played a key role in distributions of PPCPs in Baiyangdian Lake.

\section{Screening-level risk assessment}

Chronic toxicity data for detected compounds were collected and PNEC values were calculated by use of a conservative AF (Table S2), excepted for valsartan, miconazole, triamterene, clopidol, nalidixic acid, triclabendazole, and cetirizine, since ecotoxicological data were not available. The 16 PPCPs in Tai Lake and 28 PPCPs in Baiyangdian Lake were ranked, in descending order, by RQ values (Fig. 3). In the two 
lakes, a total of 7 PPCPs yielded PI values greater than zero, including carbamazepine in both lakes (Table 1).

Table 1 Prioritization of target compounds based on PI values (PI $>0)$.

\begin{tabular}{cccccc}
\hline Rank & Chemical & CAS & RQ $_{\max }$ & F (\%) & PI \\
\hline Tai Lake & & & & & \\
1 & caffeine & $58-08-2$ & 10.3 & 100 & 10.3 \\
\hline 2 & carbamazepine & $298-46-4$ & 1.9 & 70 & 1.3 \\
\hline 3 & ibuprofen & $15687-27-1$ & 1.5 & 20 & 0.3 \\
\hline Baiyangdian Lake & & & & \\
\hline 1 & sulfamethoxazole & $723-46-6$ & 1128.6 & 100 & 1128.6 \\
\hline 2 & carbamazepine epoxide & $36507-30-9$ & 25.6 & 100 & 25.6 \\
\hline 3 & carbamazepine & $298-46-4$ & 20.5 & 100 & 20.5 \\
\hline 4 & diethyltoluamide & $134-62-3$ & 10.5 & 100 & 10.5 \\
\hline 5 & triclosan & $3380-34-5$ & 1.2 & 10 & 0.12 \\
\hline
\end{tabular}

Note: $R Q_{\max }$ reference risk quotient based on the maximum measured concentration; $F$ reference frequency of PNEC exceedance; PI reference prioritization index.

In Tai Lake, three pharmaceuticals, caffeine, carbamazepine, and ibuprofen, posed risk to aquatic organisms, with $\mathrm{PI}$ values of $10.3,1.3$, and 0.3 respectively. The maximum RQ value for caffeine was 10.3 , and the frequency of PNEC exceedance was $100 \%$, which would mean that a great or moderate environmental risk at all 10 locations was probable. RQ values of carbamazepine and ibuprofen ranged from 0.63 to $1.86,0.25$ to 1.48 , and frequencies of exceeding the PNECs were $70 \%$ and $20 \%$, respectively, which indicated environmental risks in Tai Lake. Frequencies of exceedances for the remaining 12 PPCPs were zero, while that of sildenafil and diethyltoluamide presented least risk $(0.1<\mathrm{RQ}<1)$, indicated potential risk to aquatic organisms and should be paid more attention in the future.

In Baiyangdian Lake, five compounds were determined to pose measurable environmental risks, sulfamethoxazole, carbamazepine epoxide, carbamazepine, diethyltoluamide, and triclosan with $\mathrm{PI}$ values of $3454,25.6,20.5,10.5$, and 1.1 respectively. Sulfamethoxazole exhibited greater risks to nontarget organisms in Baiyangdian Lake for $100 \%$ of samples, with RQs ranged from 758 to 3,454, because of its toxic potency to Caenorhabditis elegans. Carbamazepine epoxide, carbamazepine, and diethyltoluamide represented great or moderate risks at all 10 sites, with RQs ranging from 3.2 to 25.6, 3.8 to 20.5 , and 3.2 to 10.5 , respectively. Triclosan exhibits a moderate risk $(R Q=1.2)$ in only $10 \%$ of samples, with concentrations greater than PNECs observed only at B10. Amongst target compounds, 22 PPCPs presented $\mathrm{RQ}<0.1$ for all studied samples, indicating di minimis risks to aquatic ecosystems in Baiyangdian. 
The PPCPs priority list partially overlaps with compounds prioritized in earlier studies. Eighteen PPCPs were selected and RQ values of sulfamethoxazole and carbamazepine were less than 0.01 in Baiyangdian Lake [22]. That result can be attributed to the relatively great values for PNECs of those two chemicals. In a case study performed in Europe, 42 compounds were prioritized and 5 of them can also be found in this priority list, i.e. caffeine, ibuprofen, triclosan, sulfamethoxazole, and carbamazepine [8].

\section{Probabilistic analysis of risk}

In the present study, based on prioritization indexes, caffeine, carbamazepine, diethyltoluamide, carbamazepine epoxide, and sulfamethoxazole were identified as posing great or moderate risk in Baiyangdian Lake or in Tai Lake. Therefore, they were assessed by a higher-tier assessment based on variability in exposure and ecotoxicity data. Toxicity data used were reported in Supporting Information (Table S3), and data sets were tested for log-normal distribution by use of the Shapiro-Wilk test $(p<0.05)$ prior to application of parametric statistics (Table 2). Joint probability curves for each compound, excluding carbamazepine epoxide, for which too few toxicity data were available to provide sufficient meaningful resolution, were derived by integrating the distribution for surface water concentrations with chronic toxicity effects on varies species to indicate the probability of exceeding effects of differing magnitudes (Fig. 4). Three reference lines were used to categorize risk as de minimis, lesser, intermediate or greater $[38,39]$. Each point on the curve represents both the probability that the chosen proportion of species will be affected and the frequency with which that magnitude of effect would be exceeded in surface waters.

Table 2 Parameters of joint probability curves (JPCs) for screened PPCPs

\begin{tabular}{cccccc}
\hline Chemical & N & $\begin{array}{c}\text { Mean } \\
\text { (ng/L) }\end{array}$ & SD & CV & $\begin{array}{c}\text { Shapiro-Wilk test for } \\
\text { log-normal distribution }\end{array}$ \\
\hline $\begin{array}{c}\text { exposure data set } \\
\text { Caffeine }\end{array}$ & 10 & 12.51 & 7.08 & 0.57 & 0.140 \\
\hline $\begin{array}{c}\text { carbamazepine } \\
\text { (Tai Lake) }\end{array}$ & 10 & 1.18 & 0.35 & 0.30 & 0.471 \\
\hline $\begin{array}{c}\text { carbamazepine } \\
\text { (Baiyangdian Lake) }\end{array}$ & 10 & 13.26 & 4.93 & 0.37 & 0.056 \\
\hline diethyltoluamide & 10 & 329.18 & 117.48 & 0.36 & 0.062 \\
\hline sulfamethoxazole & 10 & 1.18 & 0.35 & 0.30 & 0.194 \\
\hline toxicity data set & & & & & 0.355 \\
\hline Caffeine & 17 & 6949090 & 23411509 & 3.37 & 0.879 \\
\hline carbamazepine & 24 & 1051828 & 3858902 & 3.67 & 0.066 \\
\hline diethyltoluamide & 7 & 14724975 & 19980915 & 136 & 0.272 \\
\hline sulfamethoxazole & 9 & 68611 & 165164 & 2.41 & \\
\hline
\end{tabular}

Notes: $N$ refers to Number of data; $S D$ refers to standard deviation; $C V$ refers to coefficient of variation. 
Based on these results, the four PPCPs in the two lakes posed lesser to greater risks to aquatic organisms. Risk, based on chronic toxicity data, for sulfamethoxazole in Baiyangdian Lake was categorized as greater, with a maximum risk product of $16.62 \%$. For caffeine in Tai Lake, diethyltoluamide and carbamazepine in Baiyangdian Lake, concentrations represent intermediate risk of chronic effects with maximum risk products of $7.25 \%, 6.68 \%$, and $2.76 \%$, respectively. Lesser risk of chronic effects on aquatic organisms was identified for carbamazepine in Tai Lake, with maximum risk products of $0.82 \%$. Results from the estimated risk curves can also be used to describe the probability of exceeding various percentages of effects. The probability of exceeding $5 \%$ adverse effect depended on the most sensitive species, while the shape of the risk curve was related to ranges and variability of datasets (Fig. 5). For example, JPCs for sulfamethoxazole were classified as greater risk to more than $20 \%$ of species, but slightly above the reference line for lesser risk to $30 \%$ of species. This is because concentrations of sulfamethoxazole were only slightly greater than thresholds for adverse effects on the most sensitive species, and CVs for estimates of exposure were much less than those for relative potencies among species. In other words, ecological risk would not occur if the most sensitive species was not native species or not important for the local aquatic ecosystem. Therefore, PNEC derived by the most sensitive species and risk assessment according to RQ is likely to be over protective of aquatic ecosystems, and ecological risk assessment based on multiple species is necessary.

\section{Uncertainty Analysis}

Due to the limited measured surface water concentrations and the lack of data, for toxic potencies of some of the PPCPs to aquatic organisms, some uncertainty in conclusions reached was unavoidable. To more accurately describe exposure and ecological risks, measured concentrations of PPCPs at various temporal scales in waters are required. For seven chemicals, no conclusion can be drawn because ecotoxicological data were not available. However, environmental risks of some drugs are of concern, and due to their great frequency of detection, especially for valsartan in Tai Lake, clopidol and triclabendazole in Baiyangdian Lake. Furthermore, toxicity arising from complex mixtures of PPCPs, each of which occurred at small concentrations that would result in di minimis risks, could lead to additive or synergistic interactions, as demonstrated for similar acting compounds such as antibiotics [49]. This means that even though individual PPCPs are present in relatively small concentrations that do not elicit significant toxic effects, PPCPs mixtures can still exert considerable ecotoxicity. Further research on the risk of these detected compounds should be considered based on combined toxic. At another level, the risk that PPCPs might pose to aquatic species is not only directly related to toxicity of dissolved substances but also to possible bioaccumulation through the food web $[50,51]$. For example, bioconcentration factors measured for ibuprofen in rainbow trout (Oncorhynchus mykiss) bile were 14,000ه49,000 [52], also Coogan et al. [53] revealed accumulation of triclosan in filamentous algae species with the bioaccumulation factor ranged from 900 2,100, suggesting a high bioconcentration in aquatic organisms [54].

There were also limitations imposed by chiral chemicals that might exhibit significant differences in biodegradation and toxic potency among enantiomers [55]. The enantioselective biodegradation and ecotoxicity of chiral PPCPs tend to complicate their potential risk [56]. For example, when waters from 
several lakes and rivers in Switzerland were investigated, enantiomeric ratios (ER) of ibuprofen ranged from 0.7 to 4.2 [57]. There appears to be a trend toward lesser ERs (closer to racemic) during the warmer season, and greater ERs in winter, with concentration of S-ibuprofen higher than R-ibuprofen. Results of previous studies have shown that inhibition of prostaglandins by R-ibuprofen was 100 times than that of S-ibuprofen [58]. On the contrary, inhibition of cyclooxygenase by R-ibuprofen was 1.4 times less than that of S-ibuprofen [59]. In this study, enantioselectivity of the three chiral pharmaceuticals, caffeine, carbamazepine and ibuprofen that have potential risk in surface waters were not analyzed. Therefore, the risks of such chemicals might have been underestimated or overestimated, and this is likely to change drastically as new information becomes available. Further considerations on ecotoxicity effect of chiral pharmaceuticals in the aquatic environment are possibly needed, which could provide scientific basis and technical support to improve the accuracy of ecological risk assessment.

\section{Conclusions}

Forty-two PPCPs were positively detected in Tai and Baiyangdian Lakes, including carbamazepine, diethyltoluamide, cotinine, chlorpheniramine, and triadimefon, which were found in all the 20 sites. Concentrations were generally small and rarely exceeded PNECs, and only three chemicals, caffeine, carbamazepine, and ibuprofen, in Tai Lake and four chemicals, sulfamethoxazole, carbamazepine epoxide, carbamazepine, diethyltoluamide, and triclosan, in Baiyangdian Lake were represent a concentrations that could be hazardous to non-target organisms, with $R_{\text {max }}$ values $>1$ and $P I$ values $>0$. Based on results of the JPCs, caffeine in Tai Lake, diethyltoluamide, sulfamethoxazole, and carbamazepine in Baiyangdian Lake were categorized as greater or intermediate risk. In order to prevent over protective, it would be valuable to conduct accurate ecological risk assessment based on multiple species for screened chemicals.

\section{List Of Abbreviations}

personal care products (PPCPs)

Ultra Performance Liquid Chromatography Mass Spectrometer (UPLC-MS)

risk quotients $(\mathrm{RQ})$

prioritization index $(\mathrm{Pl})$

joint probability curves (JPCs)

personal care products (PCPs)

wastewater treatment plants (WWTPs)

index of relative socioeconomic advantage and disadvantage (IRSAD) 
solid-phase extraction (SPE)

electrospray ionization mode (ESI)

limit of detections (LOD)

limits of quantification (LOQ)

signal-to-noise ratios $(\mathrm{S} / \mathrm{N})$

no observed effect concentrations (NOECs)

$10 \%$ effect concentration $\left(\mathrm{EC}_{10}\right)$

lowest observed effect concentration (LOEC)

median effect concentration $\left(\mathrm{EC}_{50}\right)$

assessment factors (AFs)

Probabilistic Risk Assessment Tool (PRAT)

area under the risk curve (AUC)

coefficients of variation (CV)

enantiomeric ratios (ER)

\section{Declarations}

Ethics approval and consent to participate

Not applicable

\section{Consent for publication}

Not applicable

\section{Availability of data and materials}

Not applicable

\section{Competing interests}

Not applicable

\section{Funding}


This research was financially supported by the National Natural Science Foundation of China (41807400, $41977364,41521003,41630645)$, Beijing outstanding talent training program, National Major S\&T

Program for Water Pollution Control and Treatment (2017ZX07301-005). Prof Giesy was supported by the Canada Research Chairs Program of the Natural Science and Engineering Research Council of Canada (NSERC).

\section{Authors' contributions}

Na Liu was the major contributor in experiments, data analysis and manuscript writing. Na Liu and Xiaowei Jin designed the study. Zheng Yan and Ying Luo helped with the sample collection and instrumental analysis. Chenglian Feng, Zhiyou Fu and Zhi Tang contributed to data collection, evaluation and manuscript writing. Fengchang Wu and John P. Giesy contributed to improvements of the manuscript. All authors read and approved the final manuscript.

\section{Acknowledgements}

This research was financially supported by the National Natural Science Foundation of China (41807400, 41977364, 41521003, 41630645), Beijing outstanding talent training program, National Major S\&T Program for Water Pollution Control and Treatment (2017ZX07301-005). Prof Giesy was supported by the Canada Research Chairs Program of the Natural Science and Engineering Research Council of Canada (NSERC).

\section{References}

1. Boxall ABA, Rudd MA, Brooks BW, Caldwell DJ, Choi K, Hickmann S, Innes E, Ostapyk K, Staveley JP, Verslycke T, Ankley GT (2012) Pharmaceuticals and personal care products in the environment: what are the big questions?. Environmental Health Perspectives, 120(9): 1221-1229.

2. Zhang Q-Q, Ying G-G, Pan C-G, Liu Y-S, Zhao J-L (2015) Comprehensive evaluation of antibiotics emission and fate in the river basins of China: source analysis, multimedia modeling, and linkage to bacterial resistance. Environmental Science \& Technology. 9(11): 6772-6782.

3. China Industry Research Net (2012) Personal care product market development analysis. 23-24 (in Chinese).

4. Jin X-W, Wang Y-Y, Jin W, Rao K-F, Giesy JP, Hollert H (2014) Ecological risk of nonylphenol in China surface waters based on reproductive fitness. Environmental Science \& Technology. 48: 1256-1262.

5. Liu N, Wang Y-Y, Yang Q, Lv Y-B, Jin X-W, Giesy JP, Johnson AC (2016) Probabilistic assessment of risks of diethylhexyl phthalate (DEHP) in surface waters of China on reproduction of fish. Environmental Pollution. 213: 482-488.

6. Bu Q-W, Wang B, Huan J, Deng S-B, Yu G (2013) Pharmaceuticals and personal care products in the aquatic environment in China: A review. Journal of Hazardous Materials. 262(22):189-211. 
7. Liu N, Jin X-W, Wang Y-Y, Lv Y-B, Yang Q (2015) Pharmaceuticals and personal care products (PPCPS) caused reproductive toxicity in surface water of China: A review. Asian Journal of Ecotoxicology. 10(6): 900-905 (in Chinese).

8. Zhou S-B, Paolo CD, Wu X-D., Shao Y, Seiler TB, Hollert H (2019) Optimization of screening-level risk assessment and priority selection of emerging pollutants - The case of pharmaceuticals in European surface waters. Environment International. 128:1-10.

9. Choi PM, Tscharke B, Samanipour S, Hall WD, Gartner CE, Mueller JF, Thomas KV, O'Brien JW (2019) Social, demographic, and economic correlates of food and chemical consumption measured by wastewater-based epidemiology. Proceedings of the National Academy of Sciences of the United States of America. 116 (43): 21864-21873.

10. Nkoom M, Lu G, Liu J (2018) Occurrence and ecological risk assessment of pharmaceuticals and personal care products in Taihu Lake, China: a review. Environmental Science: Processes \& Impacts. 20(12): 1640-1648.

11. Shen J, Liu E, Zhu Y, Hu S, Qu W, (2007) Distribution and chemical fractionation of heavy metals in recent sediments from Lake Taihu, China. Hydrobiologia. 581(1): 141-150.

12. Zhou L-J, Wu Q-L, Zhang B-B, Zhao Y-G, Zhao B-Y (2016) Occurrence, spatiotemporal distribution, mass balance and ecological risks of antibiotics in subtropical shallow Lake Taihu, China. Environmental Science: Processes \& Impacts. 18: 500-513.

13. Song L, Chen W, Peng L, Wan N, Gan N, Zhang X (2007) Distribution and bioaccumulation of microcystins in water columns: a systematic investigation into the environmental fate and the risks associated with microcystins in Meiliang Bay, Lake Taihu. Water Research. 41: 2853-2864.

14. Zhang H, Liu M, Miao P-P, Zhou X-S, Guo L-F, Gao J-Q (2016) Analysis of spatial characteristics and source of main pollutants in Baiyangdian before and after flood season. Journal of Water Resources $\nabla$ Water Engineering, 27(5): 28-31 (in Chinese).

15. Asian Development Bank (2005) Technical Assistance to the People's Republic of China for Preparing the Integrated Ecosystem Management and Environmental Protection of the Baiyangdian Lake Catchment Project (Co-financed by the Global Environment Facility). TAR: PRC 36437.

16. Cheng W, Sheng L, Wu X, (2007) Ecological drought regime prediction and control in Baiyangdian Wetland. Presentation at the 2007 ASABE Annual International Meeting Sponsored by ASABE Minneapolis Convention Center Minneapolis, Minnesota 17-20 June 2007. An ASABE Meeting Presentation Paper No. 077095.

17. Li L, Zheng H (2002) Environmental and ecological water requirements of a river system: a case study of the Haihe-Luanhe River System. Cuadernos de Investigaci' on Geogr' afica. 28:127-136.

18. Zhong P, Yang Z, Cui B, Liu J (2005) Studies on water resource requirement for eco-environmental use of the Baiyangdian Wetland. Acta Scientiae Circumstantiae 25:1119-1126.

19. Xie Z, Lu G, Liu J, Yan Z, Ma B, Zhang Z, Chen W (2015) Occurrence, bioaccumulation, and trophic magnification of pharmaceutically active compounds in Taihu Lake, China. Chemosphere. 140:140147. 
20. Zhang P-W, Zhou H-D, Zhao G-F, Li K, Liu Q-N (2016) Spatial, temporal distribution characteristics and potential risk of PPCPs in surface sediments from Taihu Lake. Environmental science. 37(9):33483355 (in Chinese).

21. Li WH, Shi Y-L, Gao L-H, Liu J-M, Cai Y-Q (2012) Occurrence of antibiotics in water, sediments, aquatic plants, and animals from Baiyangdian Lake in North China. Chemosphere. 89(11):1307-1315

22. Zhang P-W, Zhou H-D, Li K, Zhao X-H, Liu Q-N, Liu D-J, Zhao G-F (2018) Occurrence of pharmaceuticals and personal care products, and their associated environmental risks in a large shallow lake in north China. Environmental Geochemistry \& Health. 3:1-15.

23. Wang L, Ying G-G, Zhao J-L, Yang X-B, Chen F, Tao R, Liu S, Zhou L-J (2010) Occurrence and risk assessment of acidic pharmaceuticals in the Yellow River, Hai River and Liao River of north China. Science of the Total Environment, 408(16): 3140-3147

24. Sun Q, Li Y, Li M-Y, Ashfaq M, Lv M, Wang H-J, Hu A-Y, Yu C-P (2016) PPCPs in Jiulong River estuary (China): Spatiotemporal distributions, fate, and their use as chemical markers of wastewater. Chemosphere. 150:596-604.

25. Sun J, Luo Q, Wang D-H, Wang Z-J (2015) Occurrences of pharmaceuticals in drinking water sources of major river watersheds, China. Ecotoxicology \& Environmental Safety, 117: 132-140.

26. Klimisch HJ, Tillmann U (1997) A systematic approach for evaluating the quality of experimental toxicological and ecotoxicological data. Regulatory Toxicology \& Pharmacology Rtp. 25:1-5.

27. Hobbs DA, Warne MSJ, Markich SJ (2005) Evaluation of criteria used to assess the quality of aquatic toxicity data. Integrated Environmental Assessment and Management, 1(3):174-180.

28. Moermond CTA, Kase YR, Korkaric ZM, Muris Å (2016) CRED: criteria for reporting and evaluating ecotoxicity data. Environmental Toxicology \& Chemistry, 35(5):1297-309.

29. Liu N, Jin X-W, Wang Y-Y, Wang Z-J (2016) Review of criteria for screening and evaluating ecotoxicity data. Asian Journal of Ecotoxicology. 11: 1-10 (in Chinese).

30. Jin X-W, Zha J-M, Xu Y-P, Wang Z-J, Kumaran SS (2011). Derivation of aquatic predicted no-effect concentration (PNEC) for 2,4-dichlorophenol: comparing native species data with non-native species data. Chemosphere. 84(10): 1506-1511.

31. Jin X-W, Wang Z-J, Wang Y-Y, Lv Y-B, Rao K-F, Jin W, Giesy JP, Leung M-Y (2015). Do water quality criteria based on nonnative species provide appropriate protection for native species. Environmental Toxicology and Chemistry. 34(8): 1793-1798.

32. European Union (EU) (2003) Technical guidance document on risk assessment. European Chemicals Bureau, Ispra, Italy.

33. Dulio V, von der Ohe PC (2013) NORMAN Prioritisation Framework for emerging substances. NORMAN Association, ISBN: 978-2-9545254-0-2.

34. Desbiolles F, Malleret L, Tiliacos C, Wong WCP, Laffont SI (2018) Occurrence and ecotoxicological assessment of pharmaceuticals: is there a risk for the Mediterranean aquatic environment? Science of The Total Environment. 639: 1334-1348. 
35. Tousova Z, Oswald P, Slobodnik J, Blaha L, Muz Me, Hu M (2017) European demonstration program on the effect-based and chemical identification and monitoring of organic pollutants in European surface waters. Science of the Total Environment. 601-602:1849-1868.

36. Liu N, Jin X-W, Feng C-L, Wang Z-J, Wu F-C, Johnson AC, Xiao H-X, Hollert H, Giesy JP (2020) Ecological risk assessment of fifty Pharmaceuticals and Personal Care Products (PPCPs) in Chinese surface waters: A proposed multiple-level system. Environment International. 136: 105454.

37. Ågerstrand M, Rudén C (2010) Evaluation of the accuracy and consistency of the Swedish Environmental Classification and Information System for pharmaceuticals, Science of The Total Environment. 408:2327-2339.

38. Moore DRJ, Teed RS, Rodney SI, Thompson RP, Fischer DL (2010) Refined aquatic risk assessment for aldicarb in the United States. Integr Environ Assess Manag. 6 (1):102-118.

39. Solomon K, Giesy JP (2000) Probabilistic risk assessment of agrochemicals in the environment. Crop Protection. 19:649-655.

40. Moore DRJ, Teed RS, Greer CD, Solomon KR, Giesy JP (2014) Refined avian risk assessment for chlorpyrifos in the United States. Reviews of Environmental Contamination and Toxicology, 231:163217.

41. Baker DR, Kasprzyk-Hordern B (2013) Spatial and temporal occurrence of pharmaceuticals and illicit drugs in the aqueous environment and during wastewater treatment: new developments. Science of The Total Environment. 454: 442-456.

42. Zhao J-L, Ying G-G, Liu Y-S, Chen F, Yang J-F, Wang L, Yang X-B, Stauber JL, Warne MJ (2010) Occurrence and a screening-level risk assessment of human pharmaceuticals in the Pearl River system, south China. Environmental Toxicology \& Chemistry. 29(6):1377-1404.

43. Lei K, Zhu Y, Chen W, Pan H-Y, Guo B-B, Zhang X, Cao Y-X, Sweetman AJ, Lin C-Y (2018) The occurrence of home and personal care products in the Haihe River catchment and estimation of human exposure. Science of the Total Environment. 643:63-72.

44. Qiao M, Wang C-X, Huang S-B (2006) Genotoxicity of organic pollutant water and sediment in Meiliang Bay, Taihu Lake. China Environmental Science. 26(2):224-227 (in Chinese).

45. Zhao Q-H, Hang R-R, Wang L, Qin Q (2015) Spatial differentiation of water potential energy anomaly in Taihu Lake in summer and its mechanism. China Environmental Science. 35(1):227-235 (in Chinese).

46. Guo G-H, Wu F-C, He H-P., Zhang R-Q, Li H-X (2012) Spatial distribution of ecological risk of polycyclic aromatic hydrocarbons in the surface waters of Lake Taihu. China Environmental Science, 32(6):1032-1039 (in Chinese).

47. Moiwo J P, Yang Y, Li H, Han S-M, Yang Y-M (2010) Impact of water resource exploitation on the hydrology and water storage in Baiyangdian Lake. Hydrological Processes. 24 (21):3026-3039.

48. Zhang T, Liu J-L, Wang X-M (2010) Causal analysis of the spatial-temporal variation of water quality in Baiyangdian Lake. Acta Scientiae Circumstantiae. 30(02):261-267 (in Chinese). 
49. Ferrari B, Mons R, Vollat B, Nicklas P, Giudice RL Pollio A, Garric J (2004) Environmental risk assessment of six human pharmaceuticals: Are the current environmental risk assessment procedures sufficient for the protection of the aquatic environment? Environmental Toxicology and Chemistry. 23 (5):1344-1354.

50. Ruhí A, Acuña V, Barceló D, Huerta B, Mor JR, Rodríguez-Mozaz S, Sabater S (2016) Bioaccumulation and trophic magnification of pharmaceuticals and endocrine disruptors in a Mediterranean river food web. Science of The Total Environment. 540: 250-259.

51. Zenker A, Cicero MR, Prestinaci F, Bottoni P, Carere M (2014) Bioaccumulation and biomagnification potential of pharmaceuticals with a focus to the aquatic environment. Journal of Environmental Management. 133:378-387.

52. Brozinski JM, Lahti M, Oikari A, Kronberg L (2013) Identification and dose dependency of ibuprofen biliary metabolites in rainbow trout. Chemosphere. 93: 1789-1795.

53. Coogan MA, Edziyie RE, La Point TW, Venables BJ (2007) Algal bioaccumulation of triclocarban, triclosan, and methyl-triclosan in a North Texas wastewater treatment plant receiving stream. Chemosphere. 67:1911-1918.

54. European Union (2007) Registration, evaluation, authorization and restriction of chemicals. European Parliament and Council, Brussels, Belgium.

55. Wong CS (2006) Environmental fate processes and biochemical transformations of chiral emerging organic pollutants. Analytical \& Bioanalytical Chemistry. 386: 544-558.

56. Yin L, Wang B, Ma R, Yuan H, Yu G (2016) Enantioselective environmental behavior and effect of chiral PPCPs. Progress in Chemistry. 28 (5):744-753 (in Chinese).

57. Buser HR, Thomas PA, Müller MD (1999) Occurrence and environmental behavior of the chiral pharmaceutical drug ibuprofen in surface waters and in wastewater. Environmental Science \& Technology, 33(15):2529-2535.

58. Sun T (2003) Pharmacology and toxicology evaluation of chiral drugs. Pharmaceutical Evaluation Seminar. 472-474 (in Chinese).

59. Zeng S (2002) Chiral drug and chiral pharmacology. Zhejiang University press, Hangzhou, China (in Chinese)

\section{Figures}




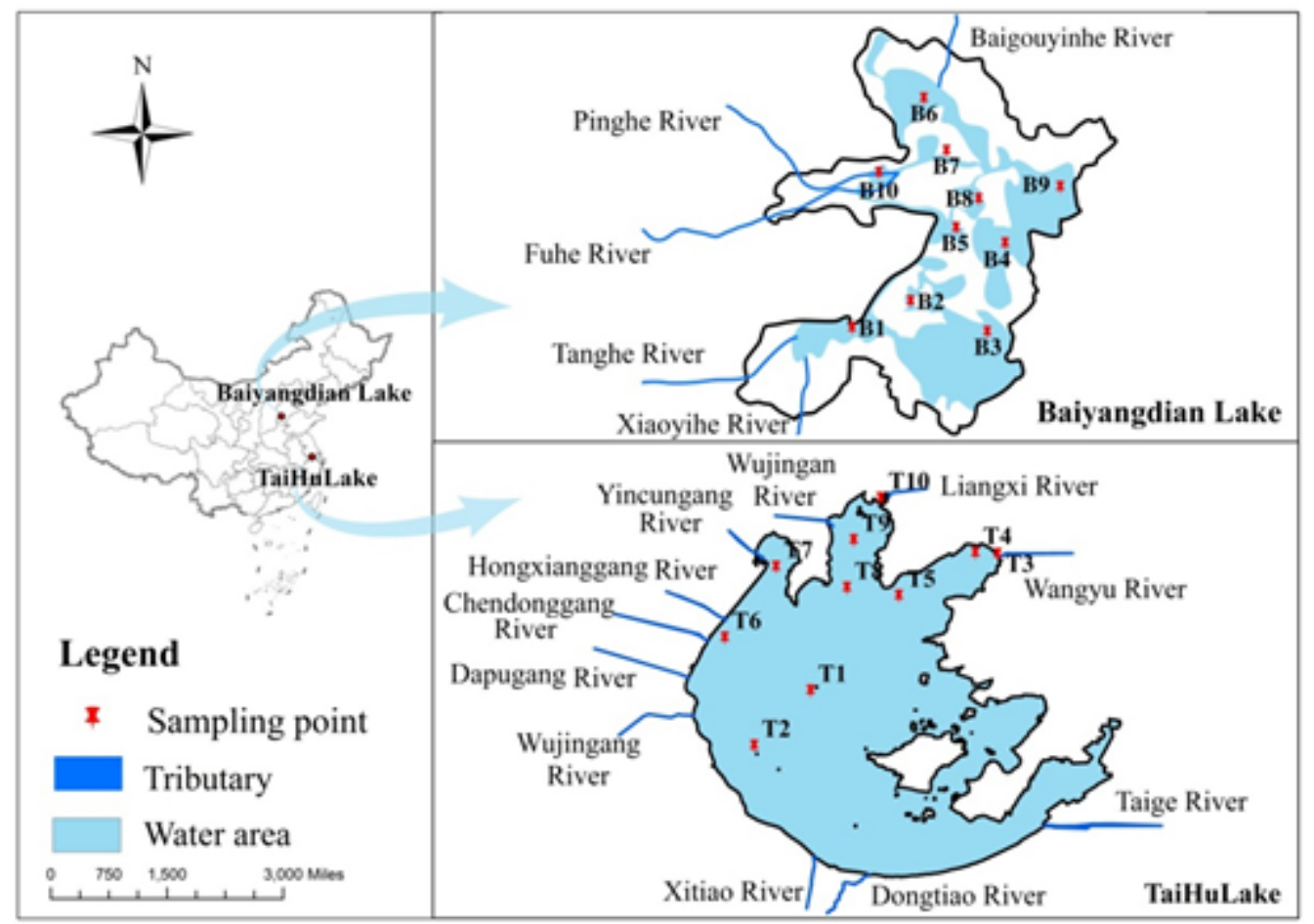

Figure 1

Map of the sampling locations for surface water in Lakes Tai and Baiyangdian. Note: The designations employed and the presentation of the material on this map do not imply the expression of any opinion whatsoever on the part of Research Square concerning the legal status of any country, territory, city or area or of its authorities, or concerning the delimitation of its frontiers or boundaries. This map has been provided by the authors.
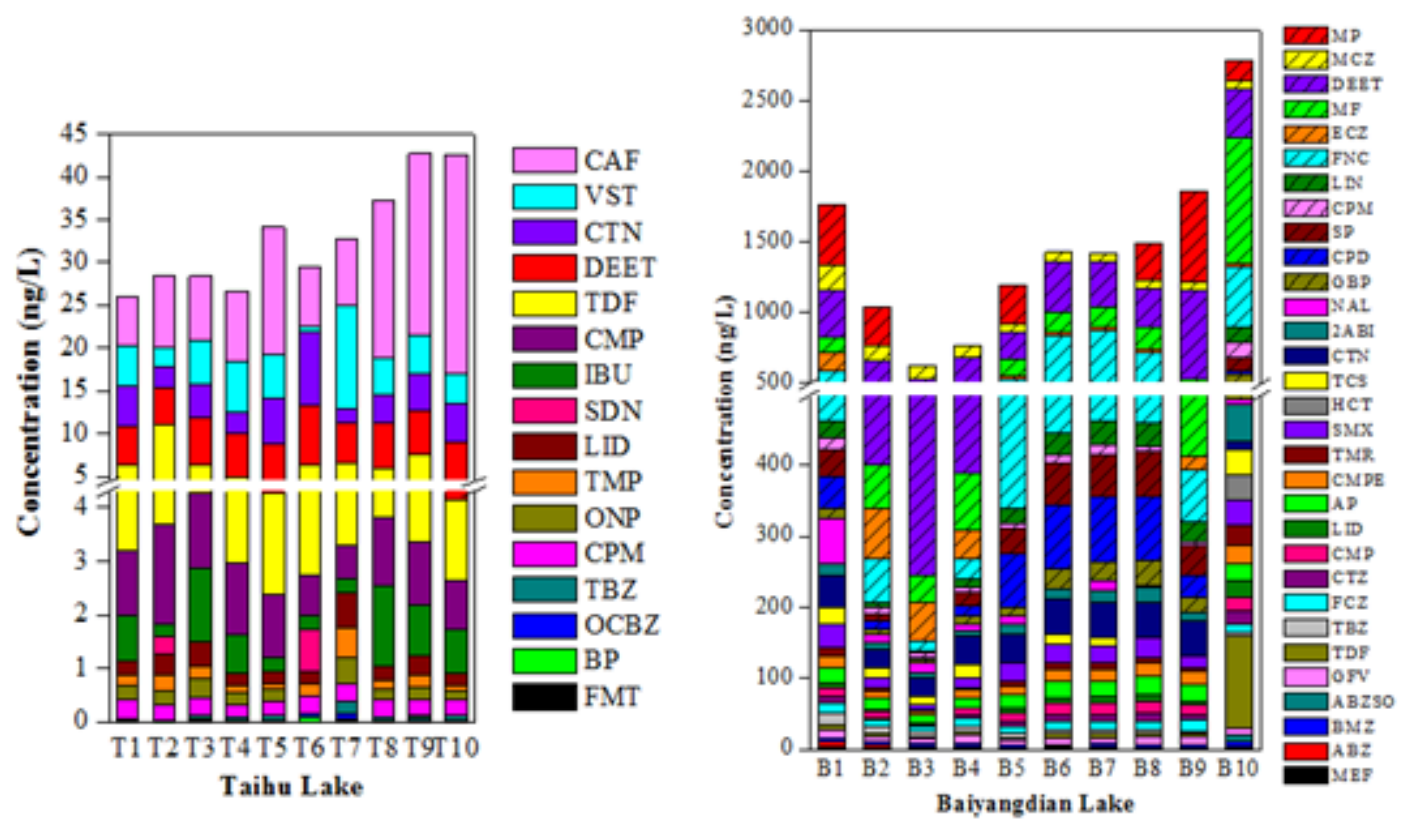

Figure 2 
Relative compositions of PPCPs in water of Tai and Baiyangdian Lakes. CAF: Caffeine; VST: Valsartan; CTN: Cotinine; DEET: Diethyltoluamide; TDF: Triadimefon; CMP: Carbamazepine; IBU: Ibuprofen; SDN: Sildenafil; LID: Lidocaine; TMP: Trimethoprim; ONP: Oxidized nifedipine; CPM: Chlorpheniramine; TBZ: Thiabendazole; OCBZ: Oxcarbazepine; BP: Butylparaben; FMT: Famotidine; MP: Methylparaben; MCZ: Miconazole; MF: Metformin; ECZ: Econazole; FNC: Florfenicol; LIN: Lincomycin; SP: Sulpiride ; CPD: Clopidol; GBP: Gabapentin; NAL: Nalidixic Acid; 2ABI: 2-Aminobenzimidazole; TCS: Triclosan; HCT: Hydrochlorothiazide; SMX: Sulfamethoxazole; TMR: Triamterene; CMPE: Carbamazepine epoxide; AP: Antipyrine; CTZ: Cetirizine; FCZ: Fluconazole; TBZ: Triclabendazole; GFV: Griseofulvin; ABZSO: Albendazole-Sulfoxide; BMZ: Benzimidazole; ABZ: Albendazole; MEF: Mefenamic acid. 


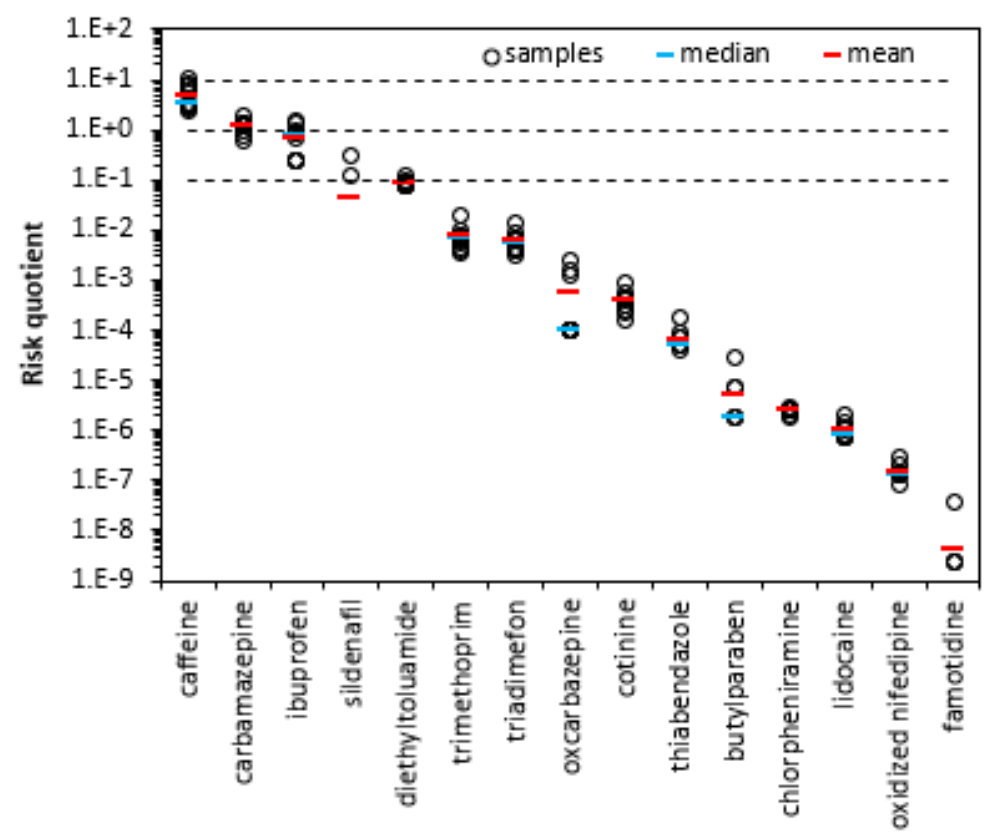

a. Tai Lake

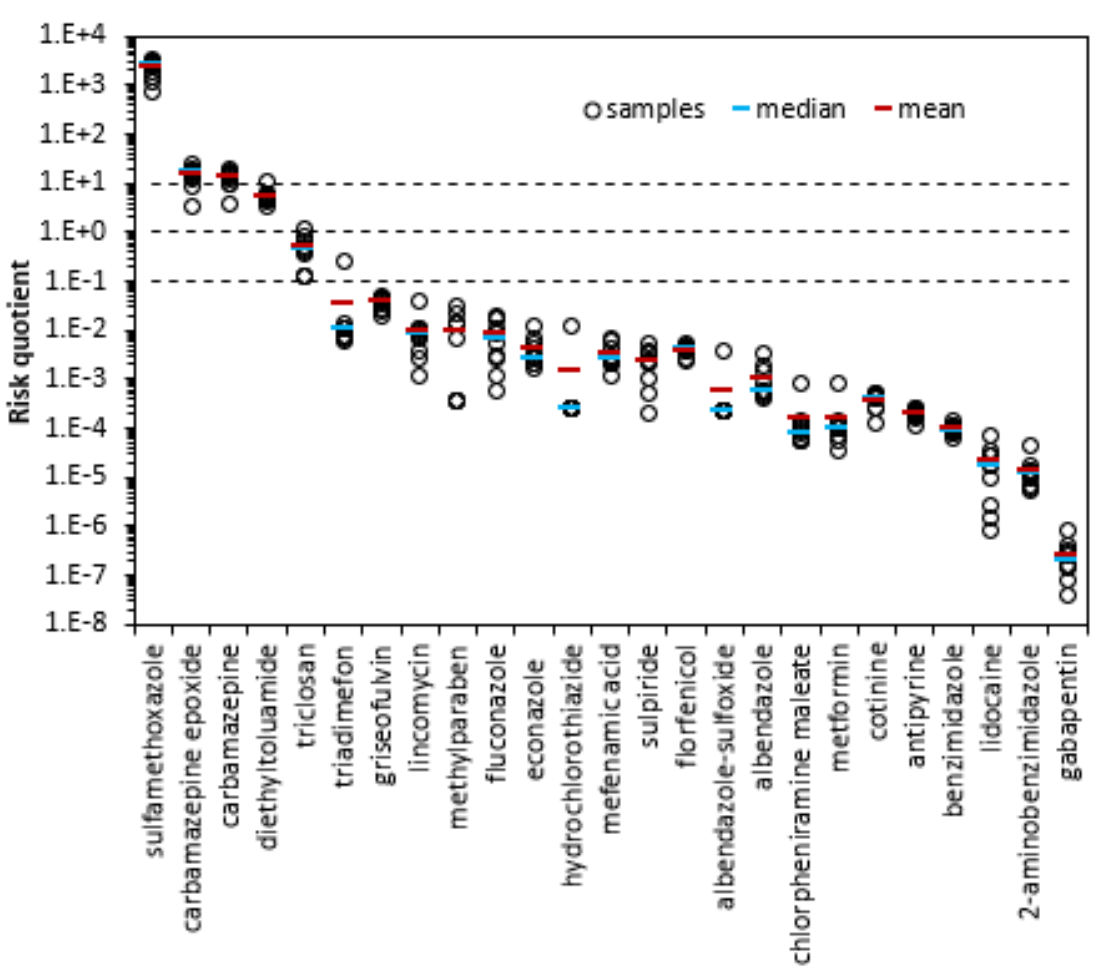

b. Baiyangdian Lake

\section{Figure 3}

Risk quotients of PPCPs in Tai and Baiyangdian Lakes of China. Concentrations of chemicals in each sample are shown as circles. Median and mean concentrations for each chemical are shown as blue and red lines respectively. 


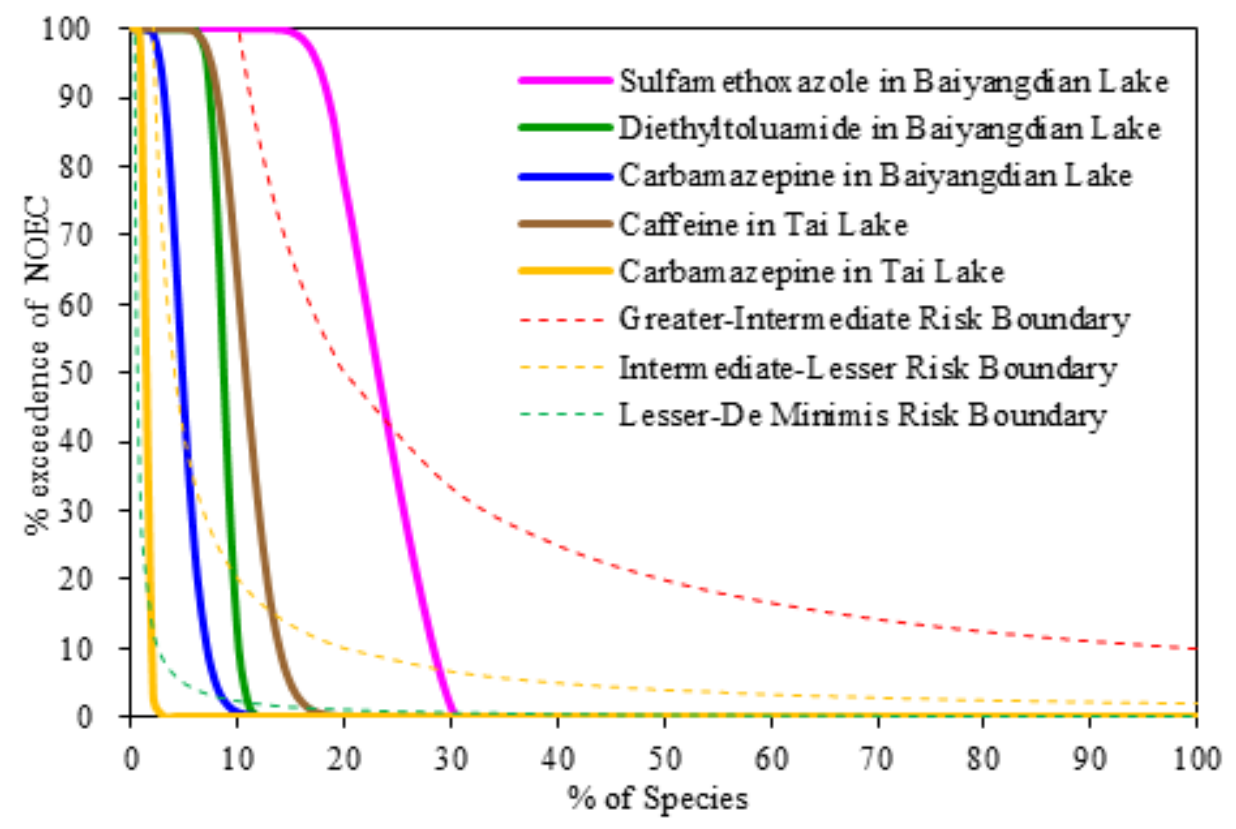

Figure 4

Joint probability curves for estimated measured environment concentrations of high prioritized PPCPs in Tai and Baiyangdian Lakes. Three reference lines were used to categorize risk as de minimis, lesser, intermediate or greater.

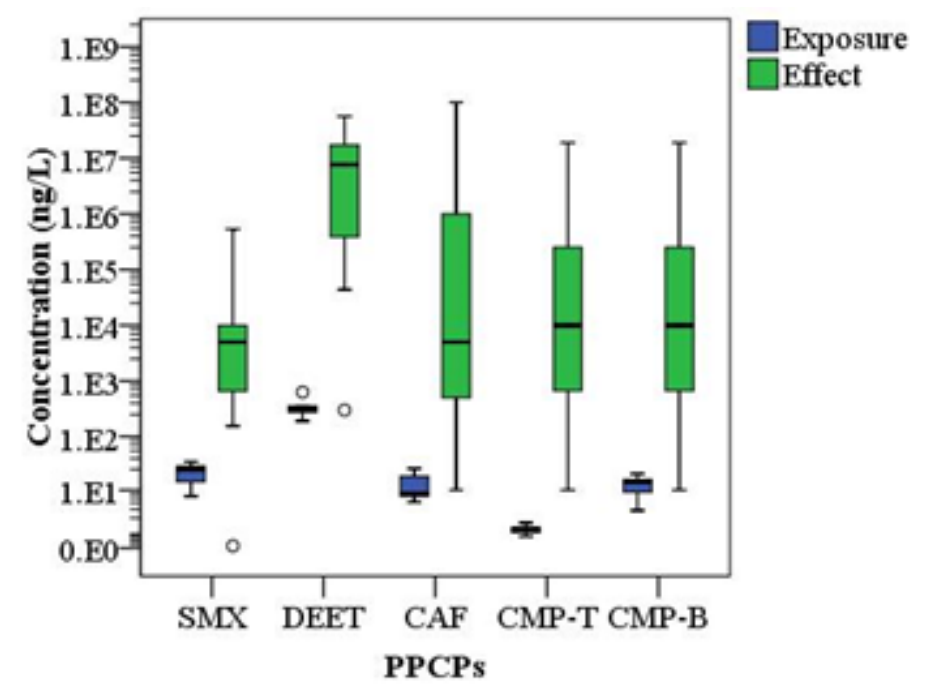

Figure 5

Comparisons among point-estimates of exposure and effects for the four high prioritized PPCPs. SMX: Sulfamethoxazole; DEET: Diethyltoluamide; CAF: Caffeine; CMP-T: Carbamazepine in Tai Lake; CMP-B: Carbamazepine in Baiyangdian Lake.

\section{Supplementary Files}


This is a list of supplementary files associated with this preprint. Click to download.

- Equations.pdf

- Supportinglnformation.pdf 